\title{
SISTEM PENGOLAHAN DATA KELOMPOK TANI KECAMATAN SUNGAI TABUK KABUPATEN BANJAR
}

\author{
Fakultas Teknologi Informasi \\ Universitas Islam Kalimantan Muhammad Arsyad Al Banjari Banjarmasin \\ Mayang Sari, S.Kom, M.Kom \\ Mayangsari.uniska@gmail.com
}

\begin{abstract}
ABSTRAK
Penelitian ini dilakukan dengan maksud untuk untuk mengatasi permasalahan yang dihadapi oleh Kelompok Tani Kecamatan Sungai Tabuk yang dikelola oleh kios Warga Tani seperti dalam melakukan proses pengelolaan data kelompok tani, memberikan informasi persediaan stok pupuk dan informasi penyaluran pupuk kepada anggota kelompok tani, serta pembuatan laporan bulanan pengeceran.

Kelompok Tani di Kecamatan Sungai Tabuk pengelolaan nya dilaksanakan oleh Kios Warga Tani yang merupakan salah satu kios di Kecamatan Sungai Tabuk yang dipilih oleh pemerintah sebagai kios resmi yang berhak mengecerkan pupuk bersubsidi kepada kelompok tani sesuai dengan HET (Harga Eceran Tertinggi) yang mana dalam menangani data kelompok tani masih menggunakan cara semi komputer dimana banyaknya tumpukan berkas yang membuat sulitnya admin dalam mengelola data sehinga admin tidak dapat menyalurkan permintaan pupuk bersubsi dari kelompok tani dengan cepat, dan kesulitan dalam memberikan informasi dengan cepat kepada kelompok tani tentang ketersedian stok pupuk selain itu data laporan pun masih mengalami kendala dalam pembuatannya dan rawannya penyelewangan pupuk bersubsidi yang disalurkan karena selama ini informasi ketersediaan pupuk hanya sebatas kepada ketua kelompok.

Metode yang digunakan dalam membangun aplikasi ini menggunakanbeberapa tahapan untuk mengumpulkan data dengan cara observasinya mengamatidan mencatat secara sistematis terhadap objek yang diteliti, tahapan selanjutnyayaitu wawancara terhadap pemilik kios, selanjutnya yaitu studi pustaka dengan caramempelajari referensi buku, artikel dan situs internet yang ada, tahapan terakhirdengan sampling dengan cara meneliti dan memilih data pada dokumen yang tersedia.
\end{abstract}

\section{Kata kunci: Kelompok Tani, Stok, Pupuk Bersubsidi}

\section{PENDAHULUAN}

Pemerintah melalui Peraturan Presiden RI No. 77 Tahun 2005 telah menetapkan bahwa tetap mempertahankan subsidi pupuk untuk petani dan mengklasifikasi pupuk / benih bersubsidi sebagai barang dalam pengawasan dan tidak bebas diperdagangkan. Produsen melalui distributor mendistribusikan kepada pengecer resmi (kios) yang telah mendapat rekomendasi melalui pupuk / benih tersebut kepada petani yang tergabung dalam kelompok tani.

$\begin{array}{rrrr} & \text { Kelompok Tani di Kecamatan } \\ \text { Sungai } & \text { Tabuk pengelolaan nya }\end{array}$ dilaksanakan oleh Kios Warga Tani yang merupakan salah satu kios di Kecamatan Sungai Tabuk yang dipilih oleh pemerintah sebagai kios resmi yang berhak mengecerkan pupuk bersubsidi kepada kelompok tani sesuai dengan HET (Harga Eceran Tertinggi). Hingga saat ini Kios Warga Tani dalam menangani data kelompok tani masih menggunakan cara 
semi komputer dimana banyaknya tumbukan berkas yang membuat sulitnya admin dalam mengelola data sehinga admin tidak dapat menyalurkan permintaan pupuk bersubsi dari kelompok tani dengan cepat, dan kesulitan dalam memberikan informasi dengan cepat kepada kelompok tani tentang ketersedian stok pupuk, selain itu data laporan pun masih mengalami kendala dalam pembuatannya dan rawannya penyelewangan pupuk bersubsidi yang disalurkan karena selama ini informasi ketersediaan pupuk hanya sebatas kepada ketua kelompok. Oleh karena banyaknya data kelompok tani yang ditangani oleh Kios Warga Tani maka, Kios Warga Tani ini memerlukan aplikasi yang dapat memanajemenkan data kelompok tani tersebut agar sistematis, akurat dan menghasilkan laporan secara cepat.

Untuk menciptakan sebuah aplikasi yang dapat memanajemenkan data secara sistematis, akurat dan cepat maka diperlukannya media tambahan atau sarana penyedia informasi seperti teknologi SMS, ada sebuah ide menarik yang banyak diadopsi dan dikembangkan, yaitu SMS Gateway. SMS Gateway hadir sebagai media atau sarana penyedia informasi berbasis SMS.

Peneliitian ini mengacu pada penelitan terdahulu yang dilakukan oleh Febby Fitri Anggrainie', Minarni, S.Kom, MM (2006) di PT. Aneka Tani yang menyatakan bahwa proses permintaan pupuk dari kelompok tani yang dilakukan secara manual membuat admin mengalami kesulitan dalam melakukan pengolahan data dan kesulitan memberitahu kelompok tani tentang ketersediaan stok pupuk.

Berdasarkan permasalahan yang di alami pada Kios Warga Tani dan mengacu pada penelitian terdahulu yang sebelumnya telah dilakukan seperti telah di uraikan di atas, maka dilakukan penelitian tentang Sistem Pengelolaan Data Kelompok Tani Kecamatan Sungai Tabuk Kabupaten Banjar.

\section{RUMUSAN MASALAH}

Sesuai permasalahan yang dikemukakan di latar belakang tersebut maka secara garis besar rumusan masalah yaitu :

1. Untuk pendataan masih dilakukan secara semi komputer sehingga sulitnya dalam membuat laporan karena data masih dalam bentuk berkas.

2. Sulitnya memberikan informasi ketersediaan stok pupuk kepada kelompok tani serta informasi penyaluran pupuk kepada anggota kelompok tani dengan cepat.

\section{TUJUAN PENELITIAN}

Tujuan penelitian ini adalah untuk mengatasi permasalahan yang dihadapi oleh Kelompok Tani Kecamatan Sungai Tabuk yang dikelola oleh kios Warga Tani seperti dalam melakukan proses pengelolaan data kelompok tani, memberikan informasi persediaan stok pupuk dan informasi penyaluran pupuk kepada anggota kelompok tani, serta pembuatan laporan bulanan pengeceran.

\section{TARGET LUARAN DAN MANFAAT PENELITIAN}

Target luaran dalam penelitian ini adalah agar nantinya penelitian ini dapat dipublikasikan ke dalam jurnal lokal maupun jurnal nasional. Sedangkan manfaat yang ingin dicapai dalam penelitian ini adalah sebagai berikut :

1. Pengolahan data Kelompok Tani Kecamatan Sungai Tabuk dapat disajikan dengan terkomputerisasi.

2. Proses indormasi ketersediaan stok pupuk kepada kelompok tani serta informasi penyaluran pupuk kepada angota kelompok tani dapat dilakukan dengan mudah dan cepat.

\section{METODE PENELITIAN}


Metode yang digunakan dalam penelitian ini adalah dengan menggunakan metode Action Research agar masalah yang dihadapi sekarang dapat dipecahkan dan dapat diperbaiki. Adapun langkahlangkah dalam pembuatan perangkat lunak ini antara lain:

1. Terjun langsung ke lapangan dengan mengunjungi Kios Warga Tani untuk mengatahui permasalahan dan mempelajari sistem yang berjalan pada objek penelitian.

2. Melihat dan menganalisa kebutuhan-kebutuhan sistem yang akan dibangun.

3. Membangun perancangan model sistem.

4. Merancang interface untuk perangkat lunak.

5. Merancang dan membuat analisis kebutuhan sistem baru.

6. Menguji dan mengimplementasikan perangkat lunak hasil rancangan ke objek penelitian.

\section{ANALISA HASIL DAN PEMBAHASAN}

\section{Hasil Penelitian}

Berdasarkan hasil analisa yang dilakukan terhadap sistem pengolahan data informasi tentang RDKK kelompok tani pada kios Warga Tani pada dasarnya masih bersifat semi komputer yang menimbulkan banyaknya tumbukan berkas. Sehingga sulitnya admin dalam mengelola data yang mengakibatkan keterlambatan pada proses penyaluran permintaan pupuk bersubsidi dari kelompok tani karena data masih dihitung secara manual, setelah data stok pupuk sudah dihitung admin memberikan informasi kepada ketua kelompok tani tentang ketersediaan stok pupuk melalui media pesan singkat berupa SMS, dimana hal itu dapat menimbulkan penyimpangan tentang stok pupuk karena informasi ketersediaan stok pupuk hanya sebatas kepada ketua kelompok. selain itu dalam pembuatan laporan masih mengalami kendala, dimana admin menghitung ulang secara manual tentang penebusan pupuk, penyaluran pupuk, dan sisa stok pupuk, sehingga dalam proses pembuatan laporan tidak begitu bisa dilakukan dengan cepat.

\section{Gambaran Sistem Usulan}

\subsection{Diagram Konteks}

Gambaran sistem usulan dalam penelitian ini digambarkan dalam diagram konteks berikut:

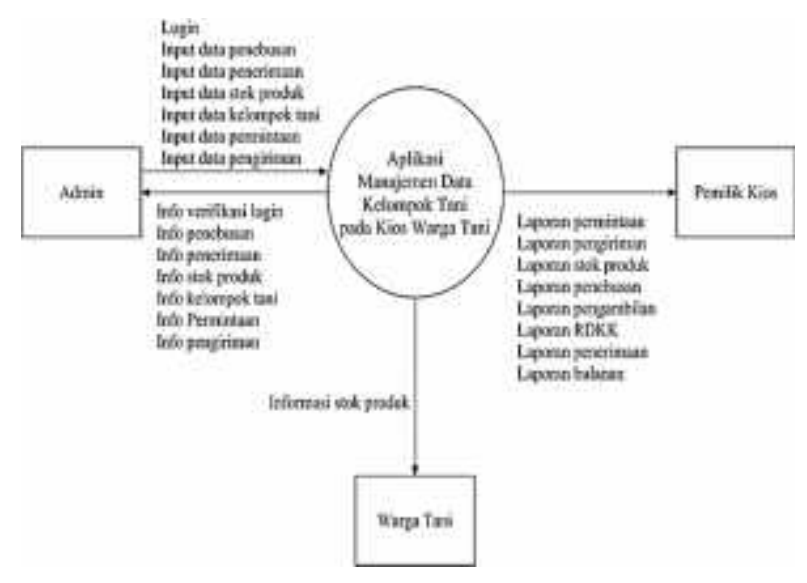

Gambar 1 Diagram Konteks

\subsection{Data Flow Diagram}




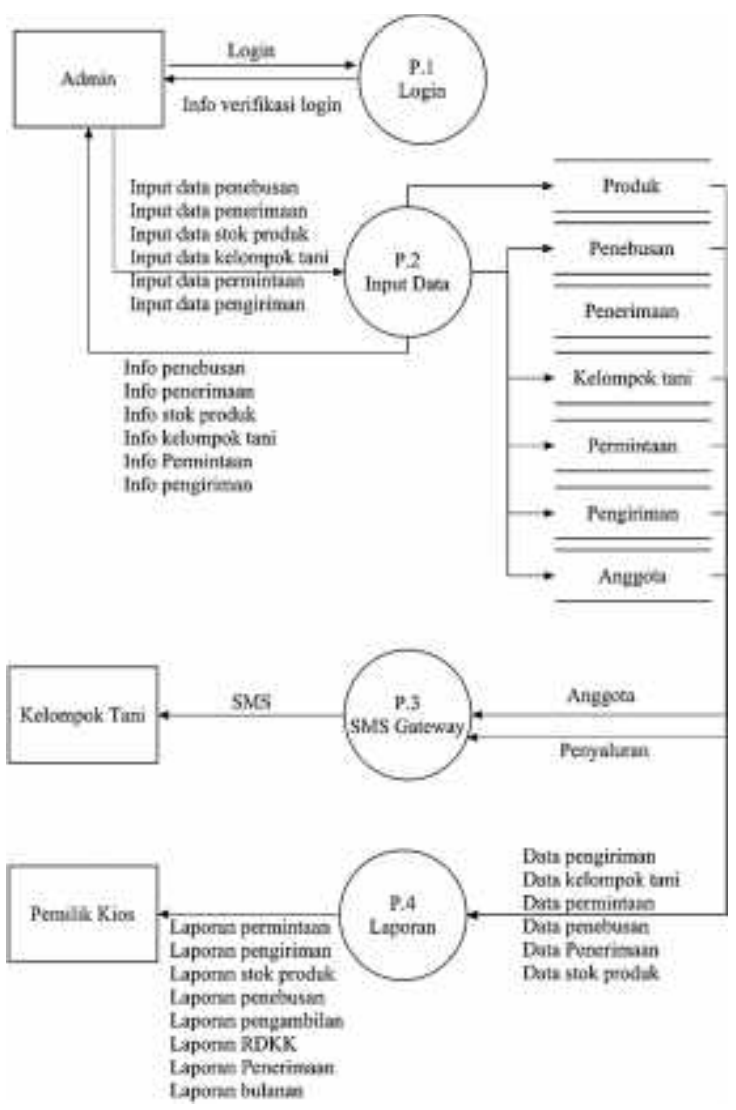

Gambar 2. Gambaran DFD Sistem Yang Akan Dibuat

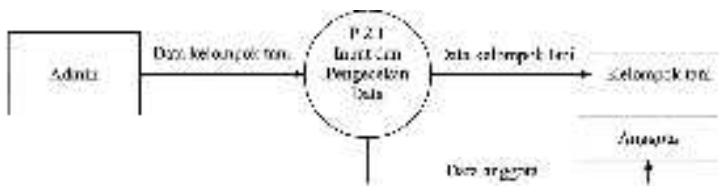

Gambar 3. Gambaran DFD Level 1 Proses 2

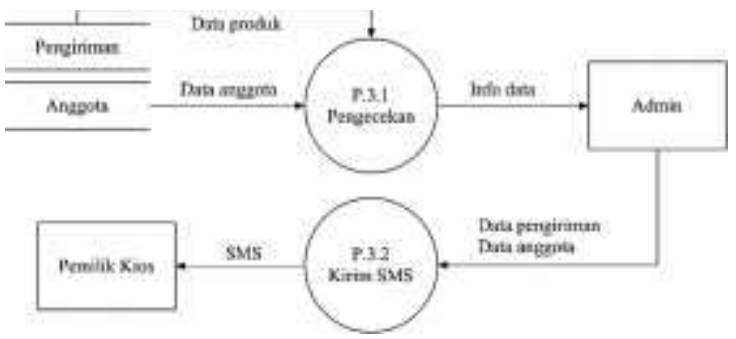

Gambar 4. Gambaran DFD Level 1 Proses 3

\section{Antar Muka Sistem}

Setelah user masuk ke dalam sistem, kemudian pengguna bisa memilih sesuai dengan kebutuhan. Didalam menu utama ini terdapat beberapa sub menu sebagai berikut:
1) Menu Utama : penerimaan barang, stok pupuk, kelompok tani, permintaan.

2) Pengiriman

3) Laporan : Laporan permintaan, laporan penerimaan barang, laporan stok pupuk, laporan pengambilan, laporan penyaluran, laporan RDKK, laporan distributor, laporan bulanan.

4) Pencarian : cari data permintaan, cari data penerimaan, cari data stok pupuk, cari data pengiriman, cari data kelompok tani.

Menu utama tersebut dapat dilihat pada gambar di bawah ini :

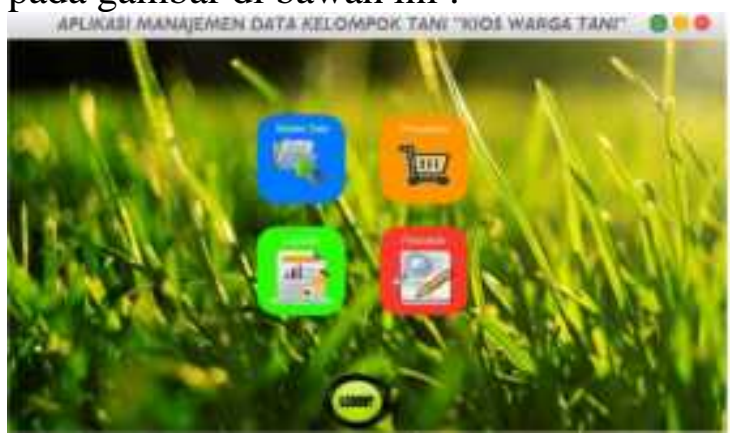

Gambar 5. Form Menu Utama

Form inputan pertama adalah Form stok pupuk. Pada form ini user menginputan data stok produk untuk mengetahui jumlah stok pupuk yang tersedia. Tampilan form stok pupuk seperti gambar di bawah ini

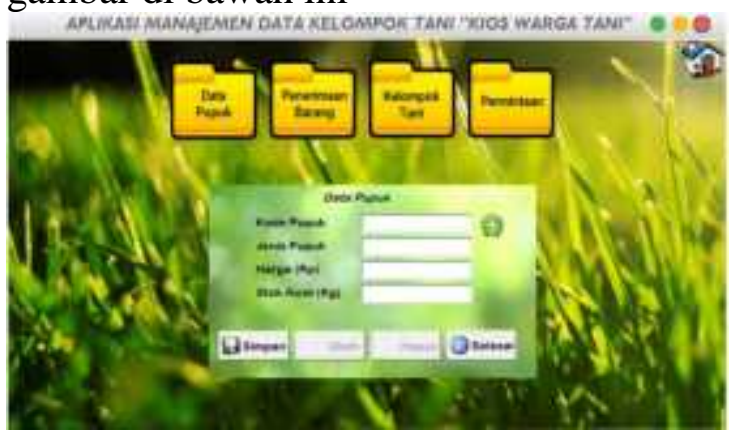

Gambar 6. Form Stok Pupuk

Form kelompok tani digunakan untuk menginputkan data kelompok tani dan anggota kelompok tani tersebut. Tampilan form kelompok tani seperti pada gambar berikut : 


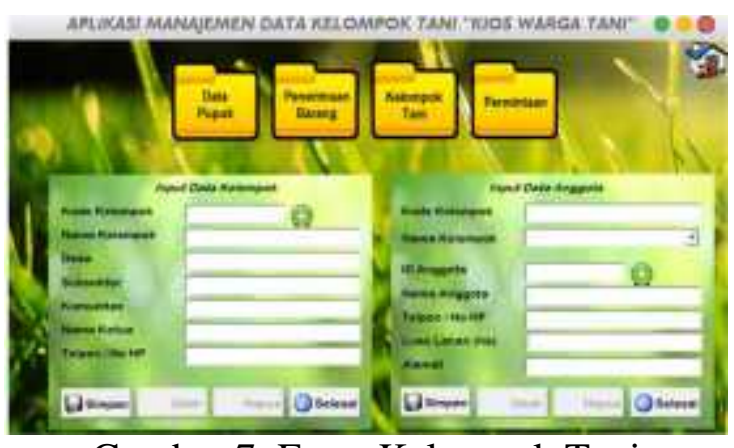

Gambar 7. Form Kelompok Tani

Form permintaan digunakan untuk menginputkan data permintaan stok pupuk dari kelompok tani. Tampilan form permintaan seperti pada gambar gambar berikut :

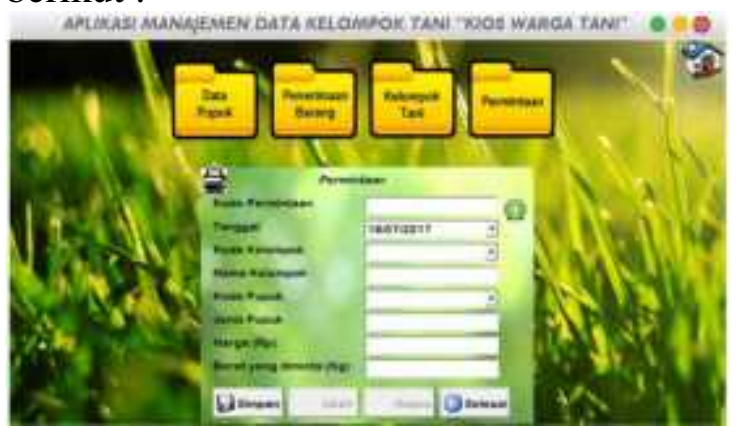

Gambar 8. Form Permintaan

Form penyaluran digunakan untuk menginputkan data penyaluran pupuk sesuai dengan jumlah permintaan dari kelompok tani, namun disalurkan secara berangsur angsur atau bertahap. Tampilan form penyaluran seperti pada gambar di bawah ini

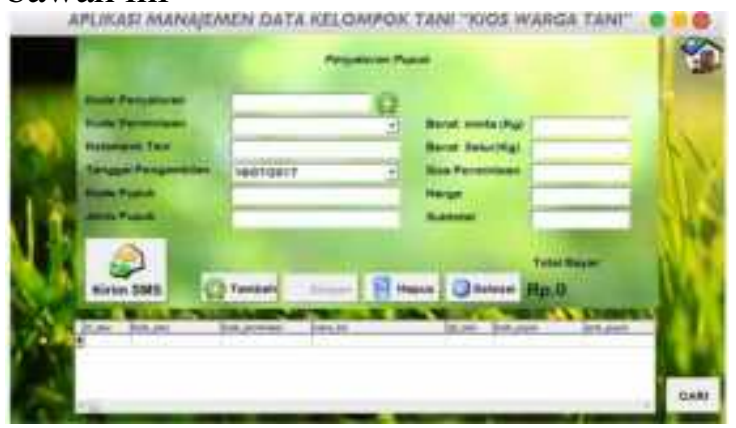

Gambar 9. Form Penyaluran
Berdasarkan hasil analisis kebutuhan aplikasi, Kios Warga Tani dapat memanajemen data secara lebih praktis, lebih terorganisir, dan terkomputerisasi yang mana di dalam aplikasi manajemen data kelompok tani yang dibuat terdapat Master Data yang terdiri dari sub menu data pupuk, penerimaan barang, kelompok tani, permintaan; Penyaluran; Laporan, yang terdiri dari sub menu laporan permintaan, laporan penerimaan barang, laporan stok pupuk, laporan pengambilan, laporan penyaluran, laporan RDKK, laporan pengeceran, serta laporan bulanan; dan Pencarian yang terdiri dari sub menu cari data permintaan, cari data penerimaan, cari data stok pupuk, cari data penyaluran, serta cari data kelompok tani sehingga dapat menghasilkan data dengan cara lebih cepat dan tepat.

\section{Saran}

Berdasarkan analisis dan kesimpulan di atas, hendaknya aplikasi manajemen data kelompok tani ini dapat dilengkapi dengan sistem penjualannya serta aplikasi ini bisa dikembangkan dengan menggunakan multi user pada pengguna sehingga tidak hanya satu pengguna saja yang bertugas memanajemen seluruh data kelompok tani.

\section{DAFTAR PUSTAKA}

Anonim. 2005. Penetapan Pupuk Bersubsidi Sebagai Barang Dalam Pengawasan, Peraturan Presiden Republik Indonesia Nomor 77 tahun 2005.

Arnie Nur Ramadhani1, Yuli Adam P. ST., MT2, Taufik Nur Adi Skom., M. (2015). Pembangunan Aplikasi Web Distribusi Kelompok Tani Katata DenganMenggunakan Metode Extreme Programming. 
Febby Fitri Anggrainie, Minarni, S.Kom., MM. (2006) Sistem Informasi Penyaluran Pupuk Bersubsidi PT. Aneka Tani Mandiri Sampit di Kabupaten Kotawaringin Timur Berbasis Web. Sampit.

Jogiyanto. (1999). Pengertian dan Definisi Aplikasi Menurut Para Ahli.

Ningsih Utami. (2011) Sistem Pemesanan Barang dengan SMS Gateway dan Aplikasi Mobile. Jakarta.

Rahendraanda Setia, ST. (2012) Pembuatan Aplikasi Sistem Monitoring Distribusi Pupuk Dan Benih Bersubsidi Menggunakan Kartu Kendali Di Departemen Pertanian. Jakarta Timur.

Selecta, Capita. (1980) Pengembangan dan Pembinaan Kelompok Tani dalam Intensifikasi Tanaman Pangan. Jakarta : Satuan Pengendali Bimas. 